\title{
КИНЕТИКА ОКИСЛЕНИЯ ИЗОПРОПИЛБЕНЗЕНА МОЛЕКУЛЯРНЫМ КИСЛОРОДОМ
}

Для разработки методов очистки вод и отходов химических предприятий от примесей детергентов и исходных веществ необходимо располагать сведениями о кинетике и элементарном механизме их окисления в естественных условиях - в нейтральной среде с участием молекулярного кислорода, при сравнительно низкой температуре и в отсутствие катализирующих агентов. В настоящем сообщении кратко изложены результаты первого этапа такого исследования, в ходе которого было проведено окисление простейшего представителя алкилароматических углеводородов изопропилбензена (кумола).

Процесс окисления кумола при участии катализаторов изучен настолько детально $\left[{ }^{1-6}\right]$, что на этой основе разработаны метод производства фенола и ацетона [4], а также промышленный синтез ацетофенона и диметилфенилкарбинола [4]. Во всех случаях основным продуктом первой стадии окисления является гидроперекись изюпропилбензена. По данным работы [1], диметилфенилкарбинол (ДМФК) образуется в итоге последующего окисления гидроперекиси, а ацетофенон - в начальной стадии, параллельно с формированием основного промежуточного продукта.

Процесс окисления протекает по свободно-радикальному механизму [3] с вырожденным разветвлением цепи и характеризуется низкой интенсивностью при невысокой температуре.

Все эти положения подлежат проверке применительно к процессу окисления изопропилбензена в указанных мягких условиях.

\section{Методика}

Экспериментальное исследование включает два основных цикла опытов. Цель первого - установить влияние температурного фактора и выявить оптимальные условия для 'дальнейшего кинетического иселедования. Опыты проведены в термостатированном герметичном реакторе (трехгорлая колба), в который вводится $50 \mathrm{M} \Omega$ исходного реагента, с дефлегматором и ловушками, при постоянной длительности $\left(10\right.$ ч) и в температурном диапазоне $20-140^{\circ} \mathrm{C}$, через каждые $20^{\circ}$. Через жидкость барботирует предварительно очищенный кислород со скоростью 2-3 мл/сек (расход измеряется ротаметром РС-3А). Температура в реакторе контролируется двумя термометрами (погрешность измерения $\pm 1,0^{\circ}$ ).

Кинетические опыты второго цикла поставлены при переменной длительности (от 1 до 10 ч) для трех температурных уровней $\left(90,100\right.$ и $\left.110^{\circ}\right)$ в «стандартной» ['] стеклянной окислительной ячейке, помещенной в ультратермостат с глицериновым заполнением, при той же скорости барботажа кислорода. Точность измерения температуры повышена ло $\pm 0,1^{\circ}$. Все опыты дублируются до получения сходящихся результатов. 
Специальное исследование показало, что расхождение результатов эксперимента, прсведенного при идентичных параметрах в обеих установках, не выходит за пределы $\pm 10 \%$. Поэтому некоторые результаты первого цикла опытов с известным отбором и корректировкой использованы также для. қинетических расчетов.

В реакционной смеси после опыта определяется содержание суммы кислородных ссединений путем обработки смесью серной и фосфорной кислот с удельным весом 1,84 и 1,70 (в объемном соотношении $1,7: 1$ ) и общий выход гидроперекиси изопропилбензена (йодометрическим методом - в уксусном ангидриде) $[7,8]$.

После удаления гидроперекиси отмывкой $30 \%$-ным едким калием при температуре 0-5 в остаточной смеси определяется выход прочих продуктов: ацетофенона по содержанию карбонильной группы (в системе солянокислый гидроксиламин-триэтаноламин), ДМФК - по содержанию гидроксильной группы (ацетилированием в пиридине и потенциометрическим титрованием в приборе «Юпитер»), фенола - после выделения щелочью в трубке Эггерса при $60^{\circ}$ колориметрическим методом.

Наличие в смеси олефинов контролируется по значению бромного числа (концентрация их настолько мала, что результаты определения выходят за пределы чувствительности метода). Следы бензойной кислоты обнаружены с помощью хроматографии в тонком незакрепленном елое окиси алюминия по восходящему принципу с последующей сушкой и установлением флюоресценции в ультрафиолетовом свете. В эксперименте использованы химически чистые реактивы. Изопропилбензен получен многократной тщательной очисткой технического продукта с перегонкой рафината и последующей проверкой чистоты по физико-химическим показателям.

\section{Результаты исследования}

Основные результаты опытов первого ци кла представлены графически на рис. 1 и 2.

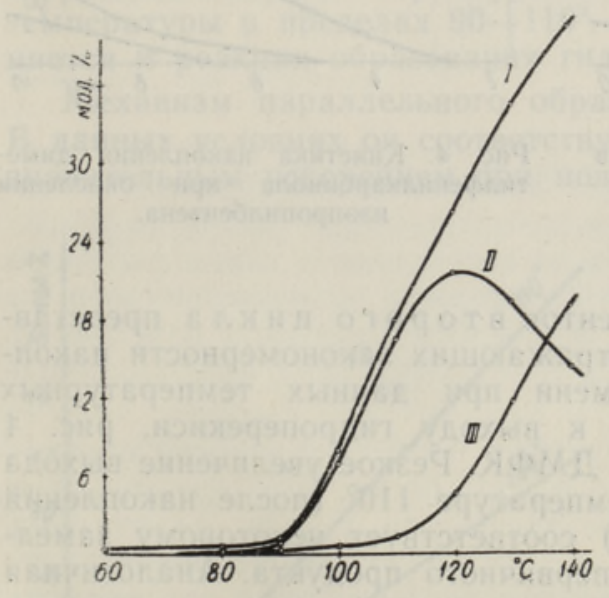

Рис. 1. Влияние температуры на выход продуктов окисления изопропилбензена (длительность опытов - $10 u)$ :

I - суммарные кислородные соединения; II - гидроперекись; III - ацетофенон.

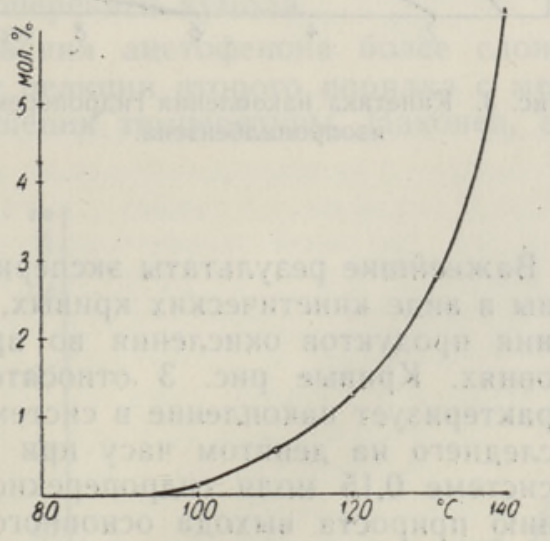

Рис. 2. Влияние температуры на выход диметилфенилкарбинола при окислении изопропилбензена (длительность опыта - 10 ч).

Образование продуктов окисления удается зафиксировать лишь начиная с температуры $60^{\circ}$, которой соответствует разложение исходного вещества на $6 \%$ (кривая I, рис. 1). Начиная с температуры $100^{\circ}$ суммарный выход продуктов окисления существенно возрастает. По дости- 
жении $120^{\circ}$ количество гидроперекиси изопропилбензена резко уменьшается вследствие неадекватного ускорения реакции ее разложения. Этому состоянию отвечает характерный максимум на кривой II (рис. 1 ). Соответственно интенсифицируется образование ДМФК - продукта распада гидроперекиси (рис. 2). Қоличество выделившегося «вторнчного» фенола, как и следовало ожидать в данных условиях, весьма мало. Оно изменяется в пределах $(1,0 \div 12,4) 10^{-4} \%$ в температурном интервале $90-140^{\circ}$.

Практически неизменное увеличение выхода ацетофенона (рис. 1, IiI) косвенно свидетельствует о формировании его на первой стадии окисления изопропилбензена, параллельно с реакцией образования гидроперекиси.

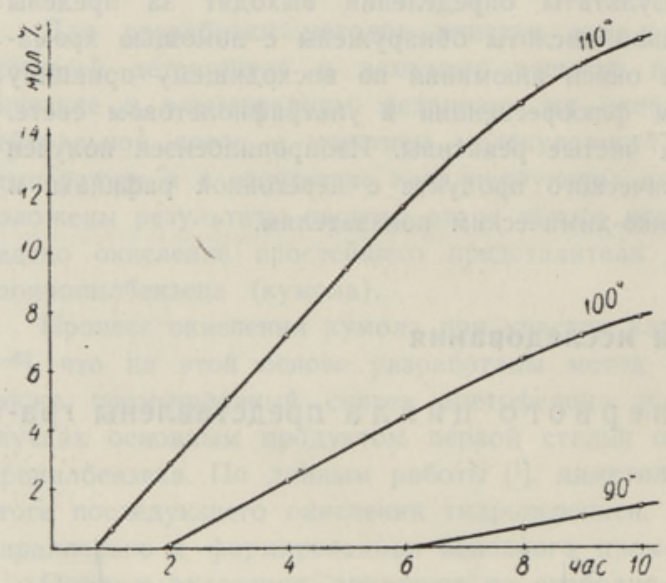

Рис. 3. Кинетика накопления гидроперекнси нзопропилбензена.

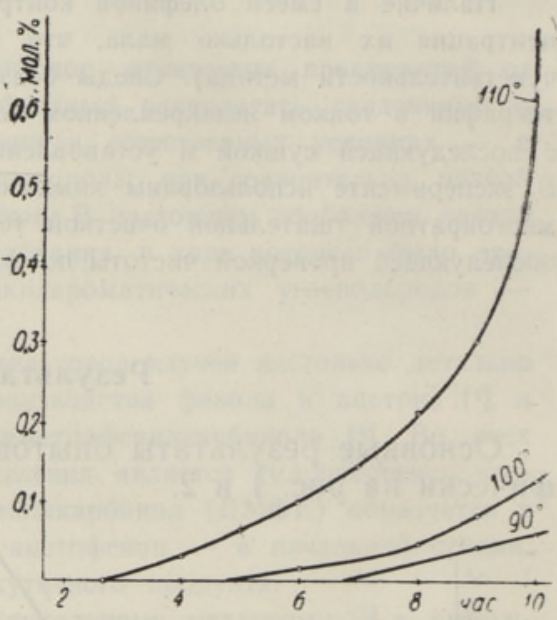

Рнс. 4. Кинетика накопления днметилфенилкарбинола при окислении изопропилбензена.

Важнейшие результаты экспериментов в торого ци кл а представлены в виде кинетических кривых, отражающих закономерности накоплєния продуктов окисления во времени при данных температурных уровнях. Кривые рис. 3 относятся к выходу гидроперекиси, рис. 4 характеризует накопление в системе ДМФК. Резкое увеличение выхода последнего на девятом часу при температуре $110^{\circ}$ (после накопления в системе 0,15 моля гидроперекиси) соответствует некоторому замедлению прироста выхода основного первичного продукта. Аналогичная го характеру закономерность наблюдается и для выхода во времени фенола в данных условиях.

Накопление же в системе ацетофенона, как показали опыты, проиеходит почти монотонно. Вопрос о кинетике и механизме его образования подробно обсужден ниже.

В начальной части всех кинетических кривых обнаруживается характерное замедление (индукционный период), обусловленное малой скоростью зарождения цепей. По мере накопления продуктов, определяющего вырожденное разветвление цепей, происходит ускорение процесса. 


\section{Обсуждение результатов}

Обработка экспериментальных данных показывает, что в изученных условиях интегральный процесс окисления протекает не в диффузионной, а в кинетической области [ $\left.{ }^{9}\right]$.

Принципиальное решение вопроса о последовательности протекания «частных» реакций и механизме формирования важнейших продуктов окисления изопропилбензена вытекает из рассмотрения рнс. 5 и 6 . На первом из них сопоставлены выходы ацетофенона, на втором - диметилфенилкарбинола по мере накопления гидроперекиси изопропилбензена. Линейный характер взаимосвязи переменных величин на рис. 5 убедительно подтверждает концепцию о параллельном образовании гидроперекиси и ацетофенона в одной - первой - стадии окисления. Интенсивный относительный рост накопления ДМФК по сравнению с первичным продуктом (см. рис. 6) свидетельствует о его вторичном происхождении.

На основании указанных представлений о механизме процесса и обработки полученных экспериментальных данных построены скорректированные графики выхода продуктов (в логарифмической шкале) во времени как для суммарного процесса, так и для «частных» реакций на первой и второй стадиях образования гидроперекиси и ацетофенона и разложения гидроперекиси кумола (лля краткости графики не приведены). Они являются основой для определения порядка реакций и вычисления значений констант их скорости. Результаты расчета представлены в нижеследующей таблице.

Как и следовало ожидать, суммарный процесс окисления изопропилбензена описывается макрокинетическим уравнением первого порядка и существенно интенсифицируется (примерно в 20 раз) с повышением температуры в пределах $90-110^{\circ}$. Аналогичной закономерности подчиняется и реакция образования гидроперекиси кумола.

Механизм параллельного образования ацетофенона более сложен. В данных условиях он соответствует реакции второго порядка с менее значительным ускорением при повышении температуры. Наконец, вто-

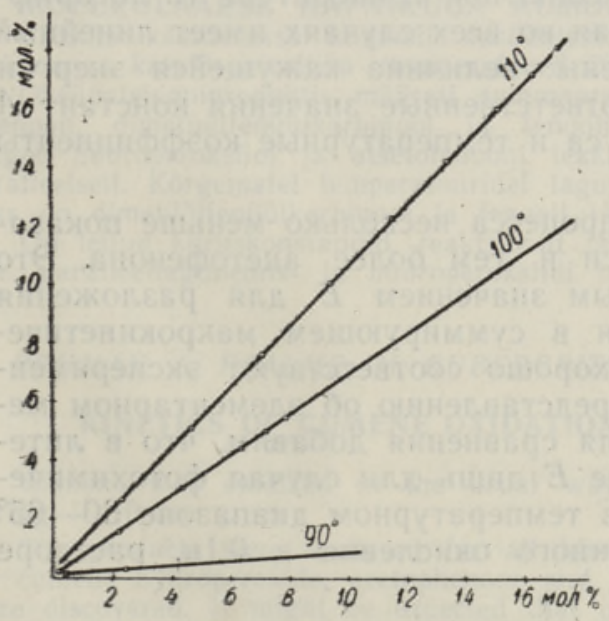

Рис. 5. Взаимосвязь накопления первичных продуктов окнсления изопропилеензена.

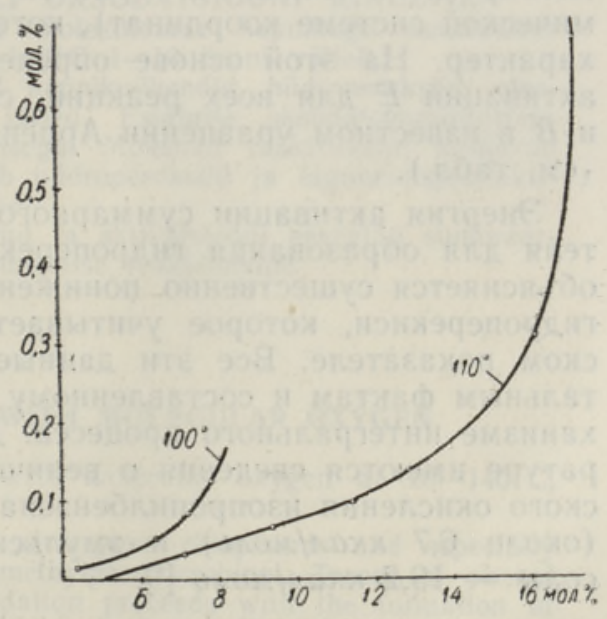

Рис. 6. Соотношение накопления диметилфенилкарбннола и гидроперемиси изопропилбензена во времени. 
ричная реакция разложения гидроперекиси кумола отвечает в данных условиях уравнению нулевого порядка. Скорость ее интенсифицируется по мере повышения температуры почти в восемь раз сильнее, чем при образовании исходного продукта на первой стадии.

Кинетическая характеристика суммарного процесса и частных реакций при окислении изопропилбензена

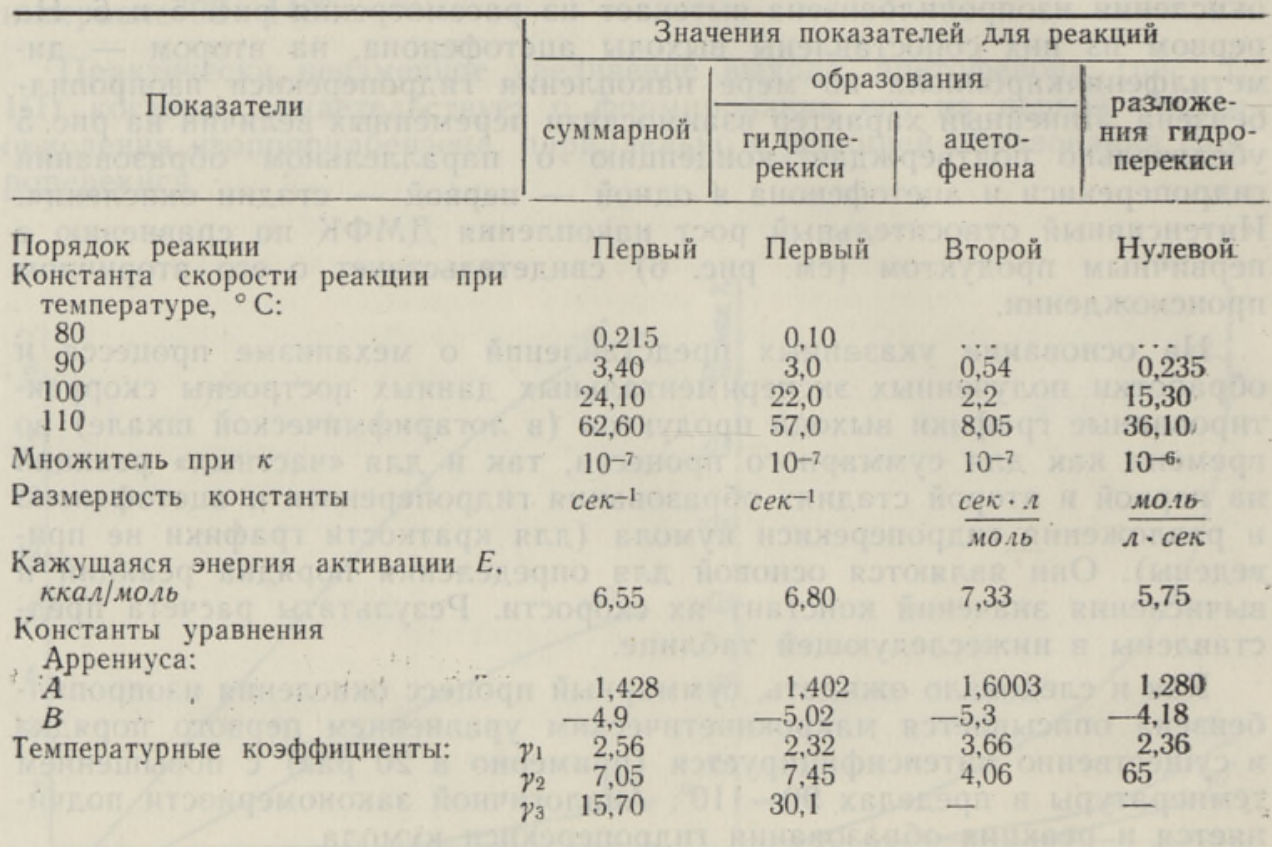

По данным для констант скорости (с привлечением материалов из первого цикла опытов при температуре $80^{\circ}$ ) построены графики их зависимости от величины, обратной абсолютной температуре (в логарифмической системе координат), которая во всех случаях имеет линейный характер. На этой основе определены: величина кажущейся энергии активации $E$ для всех реакций, соответственные значения констант $A$ и $B$ в известном уравнении Аррениуса и температурные коэффициенты (см. табл.) .

Энергия активации суммарного процесса несколько меньше показателя для образования гидроперекиси и тем более ацетофенона. Это объясняется существенно пониженным значением $E$ для разложения гидроперекиси, которое учитывается в суммирующем макрокинетическом показателе. Все эти данные хорошо соответствуют экспериментальным фактам и составленному представлению об элементарном механизме интегрального процесса. Для сравнения добавим, что в литературе имеются сведения о величине $E$ лишь для случая фотохимического окисления изопропилбензена в температурном диапазоне $30-65^{\circ}$ (около $6,7 \kappa \kappa a л /$ моль) и эмульсионного окисления в 0,1 . растворе соды - 19,2 ккал/моль [']. 


\section{Выводы}

1. Суммарный процесс окисления изопропилбензена молекулярным кислородом в нейтральной среде в отсутствие катализаторов слагается из двух последовательных стадий и соответствует макрокинетическому уравнению первого порядка.

2. Реакция образования основного первичного продукта - гидроперекиси - подчиняется тем же кинетическим закономерностям.

3. Механизм формирования второго первичного продукта - ацетофенона - более сложен, чем это принято полагать. Қинетические показатели этого процесса соответствуют реакции второго порядка.

4. Реакция разложения гидроперекиси протекает с относительно высокой скоростью с преимущественным выходом диметилфенилкарбинола и соответствует нулевому порядку. В данных условиях это характерно для реакции, обладающей резко повышенной скоростью и протекающей, по-видимому, в диффузионной области.

\section{Л И Т Е Р А Т У РА}

1. Эм ануэль Н. М., Дени сов Е. Т., М айзус 3. К., Цепные реакции окисления углеводородов в жидкой фазе, М., 1965.

2. Окисление углеводородов в жидкой фазе, Сб. статей, М.-Л., 1964.

3. Химия перекисных соединений, Сб. статей, М., 1963, с. 207.

4. Кружалов Б. Д., Голованенко Б. И., Совместное получение фенола и ацетона, М., 1963.

5. Kharasch M. S., Fono A., Nudenberg. W., J. Org. Chem., 16, 113 (1951).

6. Fordham J. W. L., Willi a m s H. L., Canad. J. Res., 27, 943 (1949).

7. Noz ok ik, Ind. Eng. Chem. Anal. Ed., 18, 583 (1946).

8. Гу бен-Вейл, Методы органической химин. Методы анализа, М., 1963.

9. С еменов Н. Н., О некоторых проблемах химической кинетики и реакционной способности, 1958.

Ннститут химии

Академии наук Эстонской ССР

\section{Поступила в редакцию} $10 / \mathrm{X} 1966$

\section{R. PRIIMAN, L. PAALME, M. GUBERGRITS}

\section{MOLEKULAARSE HAPNIKUGA KUMOOLI OKSUDATSIOONI KINEETIKA}

Artiklis käsitletakse kumooli oksüdatsiooni molekulaarse hapnikuga neutraalses keskkonnas katalüsaatoriteta (temperatuuril $20-140^{\circ} \mathrm{C} \quad 1-10$ tunni vältel).

Oksüdatsiooniproduktis määrati summaarsed hapnikuühendid, hüdroperoksiid, atsetofenoon, dimetüülfenüülkarbinool ja fenooli jäljed. Esialgne oksüdatsiooniprotsess kulgeb hüdroperoksiidi ja atsetofenooni tekkimisega. Mõlemad reaktsioonid kulgevad paralleelselt. Kōrgematel temperatuuridel laguneb hüdroperoksiid ja lagunemisproduktideks on dimetüülfenüülkarbinool ja fenooli jäljed.

On leitud kiiruskonstandid, reaktsiooni järgud ja aktivatsiooni energiad summaarsele, paralleellagunemis- ja hüdroperoksiidi lagunemise reaktsioonile.

\section{R. PRIIMAN, L. PAALME, M. GUBERGRITS}

\section{KINETICS OF CUMENE OXIDATION WITH MOLECULAR OXYGEN}

Cumene was oxidized in the usual way with molecular oxygen at $20-140^{\circ} \mathrm{C}$, during $1-10$ hours.

The products were analysed for all kinds of oxygen compounds and especially for cumene hydroperoxide, acetophenone and dimethylphenylcarbinol. Traces of phenol were discovered. It might be expected that oxidation proceeds with the formation of hydroperoxide and acetophenone as primary oxidation products. At higher temperatures hydroperoxide decomposes with the formation of dimethylphenylcarbinol and phenol.

On the basis of kinetic curves, the values of reaction rate constants and activation energies have been found. 